Article

\title{
Activation Pretreatment and Leaching Process of High-Alumina Coal Fly Ash to Extract Lithium and Aluminum
}

\author{
Shenyong Li®, Penghui Bo, Lianwei Kang, Haigang Guo, Wenyue Gao and Shenjun Qin * \\ Key Laboratory for Resource Exploration Research of Hebei Province, Hebei University of Engineering, \\ Handan 056038, China; shenyong360@hebeu.edu.cn (S.L.); bopenghui123@163.com (P.B.); \\ kanglianwei@126.com (L.K.); ghgpfdsj@163.com (H.G.); wenyue.gao@hotmail.com (W.G.) \\ * Correspondence: qinsj528@hebeu.edu.cn; Tel.: +86-0310-857-7902
}

Received: 30 May 2020; Accepted: 29 June 2020; Published: 5 July 2020

\begin{abstract}
Experiments were conducted to investigate the process of aluminum and lithium extraction from high-alumina coal fly ash (HCFA) generated from coal-fired power plants located in northern China. The presence of mullite and other aluminosilicates lead to low reactivity of coal fly ash. An activation pretreatment that destroys an inert composition of coal is necessary. The activation roasting of coal fly ash using sodium chloride and a subsequent leaching process were performed in this research. The results showed that almost no aluminum and lithium were dissolved under direct water leaching, while about $7 \%$ and $10 \%$ of those were leached into the acid solution respectively. Adding $\mathrm{NaCl}$ enhanced the atmospheric pressure leaching of aluminum and lithium with a leaching rate around $50 \%$. Phase analysis and equilibrium calculations results showed that the roasting reaction between the HCFA and $\mathrm{NaCl}$ occurred, which led to generation of main new phase $\mathrm{NaAlSi}_{3} \mathrm{O}_{8}$. The pressure extraction efficiencies of aluminum and lithium were increased to about $93 \%$ and $98 \%$, respectively. The implications of the findings provide an alternative process for recovering aluminum and lithium from readily available high-alumina coal fly ash.
\end{abstract}

Keywords: high-alumina coal fly ash; roasting activation; pressure leaching; lithium extraction

\section{Introduction}

Coal fly ash (CFA) is the main solid waste generated from coal-fired power plants, and in 2018, more than 550 million tons were discharged into the environment in China [1]. With the continuous development of industry, the total accumulated CFA has exceeded 3 billion tons [2]. The huge quantities of CFA occupy a large volume in landfills, and lead to environmental pollution risks. Meanwhile, typical high-alumina CFA (HCFA) is released in northern China, and the content of $\mathrm{Al}_{2} \mathrm{O}_{3}$ can be as high as $40-50 \%$ aluminum and more than $0.2 \%$ lithium [3]; it is considered to be a potential substitute for bauxite in alumina production [4]. Recovering aluminum from HCFA could meet the great demand for aluminum in future industry needs. The distribution of lithium-containing minerals in HCFA is relatively uniform and strongly correlated to $\mathrm{Al}$ and $\mathrm{Si}$ contents [5,6]. A continuous and sharp increase in the demand for lithium is expected in future clean energy technologies [7]. Exploring extraction techniques for aluminum and lithium from HCFA is a promising way to achieve an impact on environmental pollution via recycling and reduction.

To date, many technologies have been proposed that are in line with the properties of raw CFA. Because CFA is rich in mullite and insoluble minerals, direct acid or alkali leaching does not work well and leads to a low leaching rate, large acid consumption, high temperature, and so on. Hence, preprocessing technologies—such as sintering, desilicification, and magnetic separation—are used to 
improve reaction activity of the CFA and to separate many impurities (Fe, $\mathrm{Si}$, etc.). These have mainly been applied for aluminum extraction, and the sintering processes can be classified into limestone and lime-soda sintering process, combined predesalination and lime-soda, and ammonium sulfate sintering process [8-10]. Furthermore, a mild hydrochemical process using $\mathrm{NaOH}$ and $\mathrm{Ca}(\mathrm{OH})_{2}$ was developed for aluminum extraction. However, large amounts of silica and calcium slag will be produced, so acidic, alkali, and acid-alkali combination processes were deeply investigated in the past few years $[6,10,11]$.

The major feedstock for commercial lithium production can be obtained from high-grade lithium ores (such as spodumene, petalite, lepidolite, etc.) and lithium rich salt-lake brines and geothermal waters with the Li concentration range of 0.1-2.2 $\mathrm{g} / \mathrm{L}$ [12]; however, lithium recovery from seawater is not cost-effective because of the low concentration, which is around $0.17 \mathrm{mg} / \mathrm{L}$ [13]. The lithium exploitation from HCFA develops a new source of lithium, and concentrations of $\mathrm{Li}_{2} \mathrm{O}$ are up to $0.2-0.83 \%$ in the ashes of some Li-rich coal deposit [14]. At present, there are many related reports in the literature regarding the extraction of aluminum and silicon from CFA [10,14], but there are fewer studies about lithium recovery from HCFA. The Li recovery process from ores broadly consists of mineral beneficiation and extractive metallurgy. Roasting/calcinations or a chlorination process were reported to extract $\mathrm{Li}$ in the literature $[12,13]$. HCFA may have better application prospects when aluminum and lithium are extracted simultaneously.

In this paper, a roasting and pressure acid leaching process are employed to maximize the extraction efficiency of lithium and aluminum. Direct water and acid leaching experiments are conducted to compare the extraction efficiency with that of the pressure acid process. Phase transformations during the roasting process were acquired via global chemical equilibrium calculations using FactSage 7.0. A comprehensive understanding of the leaching behavior of HCFA would greatly contribute to roasting with sodium chloride, and this study could also serve as a reference for the recovery of other elements.

\section{Materials and Methods}

\subsection{Materials}

A typical HCFA was used in this work. It was obtained from coal-fired power plants in Shanxi Province, China, and was collected from the discharge part that is located after the baghouse filters of the circulating fluid bed combustors. The chemical composition was determined via XRF analysis and is listed in Table 1. As shown in the Table 1, the HCFA is mainly composed of $44.12 \% \mathrm{SiO}_{2}, 42.17 \%$ $\mathrm{Al}_{2} \mathrm{O}_{3}, 2.44 \% \mathrm{CaO}$, and $2.43 \% \mathrm{Fe}_{2} \mathrm{O}_{3}$, and the content of lithium oxide was $0.2 \%$. The total amount of alumina and silica accounts for more than $85 \mathrm{wt} \%$ of the HCFA. In addition, it also contained small amounts of unburnt carbon.

Table 1. Chemical composition of high-alumina coal fly ash.

\begin{tabular}{ccccccccccc}
\hline Component & $\mathrm{Al}_{\mathbf{2}} \mathrm{O}_{3}$ & $\mathrm{SiO}_{2}$ & $\mathrm{Fe}_{2} \mathrm{O}_{3}$ & $\mathrm{TiO}_{2}$ & $\mathrm{CaO}$ & $\mathbf{M g O}$ & $\mathbf{P}_{\mathbf{2}} \mathrm{O}_{5}$ & $\mathbf{N a}_{2} \mathrm{O}$ & $\mathbf{L i}$ & LOI \\
\hline Content $\%$ & 44.12 & 42.17 & 2.43 & 1.67 & 2.44 & 0.68 & 0.69 & 0.14 & $933 \mu \mathrm{g} / \mathrm{g}$ & 2.1 \\
\hline
\end{tabular}

$\mathrm{HCl}, \mathrm{HNO}_{3}, \mathrm{HF}$, and $\mathrm{HClO}_{4}$ were guaranteed reagent grade, and all the other reagents used in this study were analytical grade. Deionized water was used for the experiments. All of the chemicals were obtained from commercial sources and were used as received without further purification.

\subsection{Experimental Procedure}

The HCFA samples were first dried in an oven at $105^{\circ} \mathrm{C}$ for $24 \mathrm{~h}$, and then the HCFA powders and sodium chloride were thoroughly mixed in a blending bottle with a mass ratio of 1:1, 1:2, and 2:1. The mixtures were transferred into a covered corundum crucible, and then heated with the temperature from 500 to $1000{ }^{\circ} \mathrm{C}$ for $2 \mathrm{~h}$ in a muffle furnace; then, they were cooled naturally to ambient temperature. The roasted mixtures were removed, ground, and sieved to sizes lower than $100 \mu \mathrm{m}$. The mixtures were then used for leaching and extraction. 
To determine comparative conditions of direct leaching and roasted leaching, the direct leaching test was carried out under water leaching and acid leaching for $60 \mathrm{~min}$ with various concentrations of hydrochloric acid. All of the water and direct acid leaching experiments were conducted in batch mode in a $300 \mathrm{~mL}$ Erlenmeyer flask reactor, which was heated using a water bath equipped with a temperature control $\left( \pm 1^{\circ} \mathrm{C}\right)$ system and an electromagnetic agitator. The reactor was also equipped with a condenser to prevent solution loss via evaporation at relatively high temperature. The S/L ratio, temperature, magnetic stirring speed, and leaching time of water leaching were kept constant at 1:20, $90^{\circ} \mathrm{C}, 400 \mathrm{rpm}$ and $1 \mathrm{~h}$, respectively [15]. When the selected temperature was reached, the roasted sample was added to the reactor, and leaching was begun. The leaching process was used to evaluate the roasting validity.

The pressurized extraction experiments of the samples were conducted in $0.05 \mathrm{~L}$ sealed hydrothermal reaction kettles that were fitted with polytetrafluoroethylene-lined pots. The kettles were placed in an electrothermal blast oven that was heated to the target temperature. All of the experiments were carried out batch-wise using $1 \mathrm{~g}$ of roasted HCFA with acid extraction. The self-pressure in the kettle was generated with the evaporation of acid solution driven by the temperature. After pressure acid extraction, vacuum filtration was employed to dewater the leaching residues, which were then thoroughly washed with deionized water three times and then dried at $105^{\circ} \mathrm{C}$ until they were a constant weight.

\subsection{Characterizations}

The particle size distribution was measured using a laser particle sizer (LPS, Analysette 22 MicroTec plus, Fritsch, Germany), which has a measuring range of 0.8-2000 $\mu \mathrm{m}$.

The phases in the HCFA, calcined samples and leaching residue were characterized using an X-ray diffractometer (XRD, D/Max-2200, Rigaku, Japan) equipped with a $\mathrm{Cu}$ K $\alpha$ radiation source $(\lambda=0.1542 \mathrm{~nm})$ and a diffraction beam monochromator. The acceleration voltage was $40 \mathrm{kV}$, and the electrical current was $30 \mathrm{~mA}$. The step-scan covered the angular range of $5-70^{\circ}(2 \theta)$ with a step size of $0.02^{\circ}$, and the scan speed was $8^{\circ} \mathrm{min}^{-1}$. The XRD diffraction patterns were analyzed using “Match!"software (V3.4.2, Crystal Impact, Bonn, Germany) based on the PDF2 database.

The chemical composition of samples was determined using wavelength dispersive-X-ray fluorescence (WD-XRF, ARL Perform'X 4200, ThermoScientific, Madison, WI, USA). Samples were irradiated with X-ray emission from a Rhodium tube with a maximum power of $4200 \mathrm{~W}$. The microstructure and morphology of the samples were characterized using a scanning electron microscope (SEM, SU8200, Hitachi, Tokyo, Japan) with a Hitachi UHR FE-SEM SU8220 system operated at $10.0 \mathrm{kV}$.

For the acid wet-digestion procedure, $1 \mathrm{~g}$ of an HCFA sample and a mixture containing $4 \mathrm{~mL}$ of $\mathrm{HNO}_{3}, 12 \mathrm{~mL}$ of $\mathrm{HCl}, 8 \mathrm{~mL}$ of $\mathrm{HClO}_{4}$, and $6 \mathrm{~mL}$ of $\mathrm{HF}$ was placed in a $50 \mathrm{~mL}$ PTFE tube according to the GB/T 17141-1997 standard to achieve efficient and complete digestion. The concentrations of $\mathrm{Al}$ and Li were determined using an atomic absorption spectrometer (AAS, TAS-990 Super, Pgeneral, Beijing, China). The instrument was calibrated using standard solutions, and it was adjusted to $309.3 \mathrm{~nm}$ for $\mathrm{Al}$ and to $670.8 \mathrm{~nm}$ for Li. For samples with very high levels of Al, digested soil solutions were diluted by a factor of 1000 to bring them within the calibration range.

The leaching rate or extraction efficiency of elements was calculated as

$$
\eta_{\mathrm{E}}=\frac{\mathrm{m}_{1} \times \mathrm{w}_{1}}{\mathrm{~m}_{0} \times \mathrm{w}_{0}} \times 100 \%
$$

where $\eta_{\mathrm{E}}$ denotes the leaching rate or extraction efficiency of $\mathrm{Al}$ and $\mathrm{Li}, \mathrm{m}_{0}$ is the mass of the raw sample, $\mathrm{m}_{1}$ is the mass of the residue, $\mathrm{w}_{0}$ is the $(\mathrm{Al}, \mathrm{Li})$ content in the HCFA, and $\mathrm{w}_{1}$ is the $(\mathrm{Al}, \mathrm{Li})$ content of the extracted solution. 


\subsection{Thermodynamic Simulation}

To understand the multi-phase equilibria and mineral phase transformations during the roasting process, the commercial thermodynamic equilibrium program FactSage 7.0 was employed to simulate the phase changes (between gas, solid and liquid phase) of individual elements, including $\mathrm{Al}, \mathrm{Li}$, and Na with increasing temperature. Also, their compositions were based on the minimization of the Gibbs free energy [16]. The reaction and equilibrium module were mainly used for predicting the phase transformations. The elemental composition of the HCFA was used as the input reactants listed in Table 1, and the conditions were set to be the same as at atmospheric pressure conditions in an open system from $400{ }^{\circ} \mathrm{C}$ to $1100^{\circ} \mathrm{C}$.

\section{Results and Discussion}

\subsection{HCFA Characterization}

The size distribution of HCFA particles is illustrated in Figure 1; the figure shows different particle-size groups and a cumulative distribution curve. When plotted on a linear scale, the cumulative distribution reveals a quick increase, and the curve remains asymptotic to $100 \%$. Particle sizes below $100 \mu \mathrm{m}$ account for most of the variation $(99.7 \%)$ in all of the materials studied, and the median particle size $\left(D_{50}\right)$ was $33.2 \mu \mathrm{m}$ with a $\mathrm{D}_{90}$ value of about $73.9 \mu \mathrm{m}$. The HCFA particles showed a remarkable increase in cumulative distribution curve within the particle size range of 19.2-57.6 $\mu \mathrm{m}$.

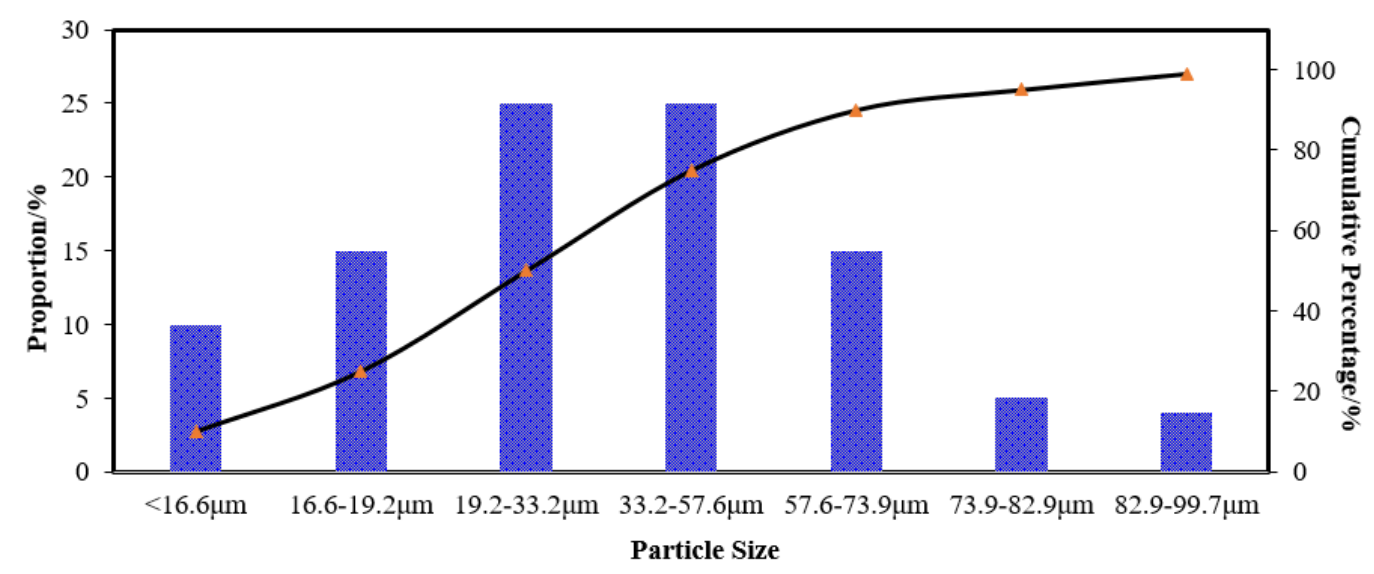

Figure 1. Size distribution of high-alumina coal fly ash.

Figure 2 shows that the major crystalline phases in the HCFA samples were mullite and quartz, which showed higher crystallinity and accounted for $83.9 \%$ and $12.2 \%$, respectively. The peaks at $2 \theta=16.2^{\circ}, 26.3^{\circ}, 33.2^{\circ}, 35.2^{\circ}, 40.8^{\circ}, 60.7^{\circ}$, and $64.6^{\circ}$ could be clearly indexed as mullite phase, and the peaks at $2 \theta=20.8^{\circ}, 26.6^{\circ}, 39.4^{\circ}, 50.1^{\circ}, 58.3^{\circ}$, and $64.0^{\circ}$ were ascribed to quartz. It was found that $3.9 \%$ of the sample was identified as corundum phase. The large proportion of the glass phase in the HCFA sample is attributed to the high temperature of the synthesis reaction between the alumina-silica system [17]. 


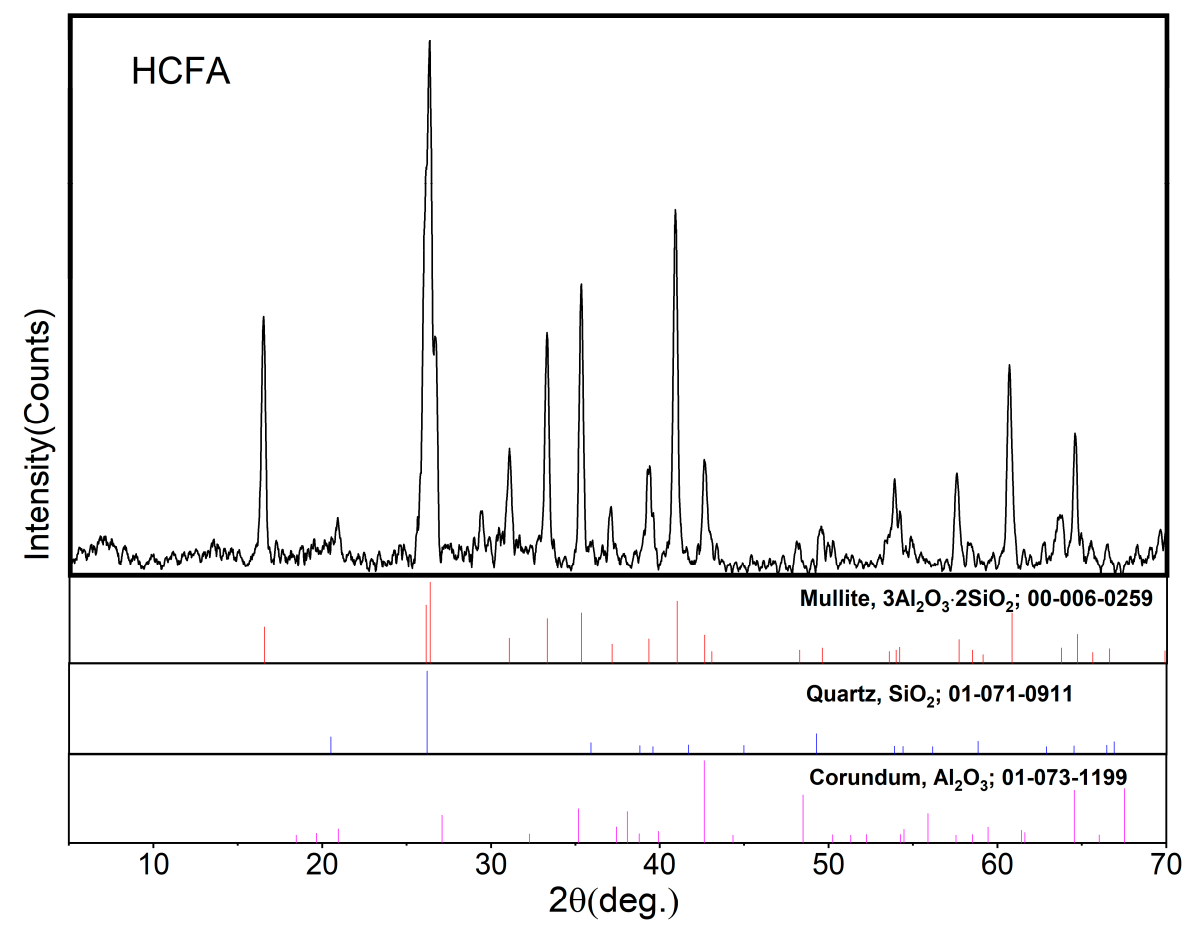

Figure 2. XRD pattern for HCFA.

\subsection{Direct Water and Acid Leaching}

In the water leaching procedure, aluminum and lithium were hardly leached out of HCFA, and the leaching rate was about $0.6 \%$. From the XRD results for HCFA, it was found that the vast majority of the Al-rich phase was mullite, which is very stable and insoluble in both water and concentrated acids. Figure 3 indicates that with an increasing in the $\mathrm{HCl}$ concentration, the leaching rate of $\mathrm{Al}$ and Li both increased slowly and were below $5 \%$ and $7 \%$, respectively. This is because most of the Li was found in the glass phase and was strongly correlated to $\mathrm{Al}$ and $\mathrm{Si}[3,5]$. Hence, it is difficult to dissolve Li-bearing mineral into solution via direct washing and acid leaching. However, when the HCFA was roasted alone at $800{ }^{\circ} \mathrm{C}$, the leaching rate of $\mathrm{Al}$ and $\mathrm{Li}$ was slightly improved, and the leaching efficiencies of $\mathrm{Al}$ and $\mathrm{Li}$ were no more than $7 \%$ and $10 \%$, respectively. The previous work [4] showed that thermal activation of coal fly ash had little effect on aluminum extraction.

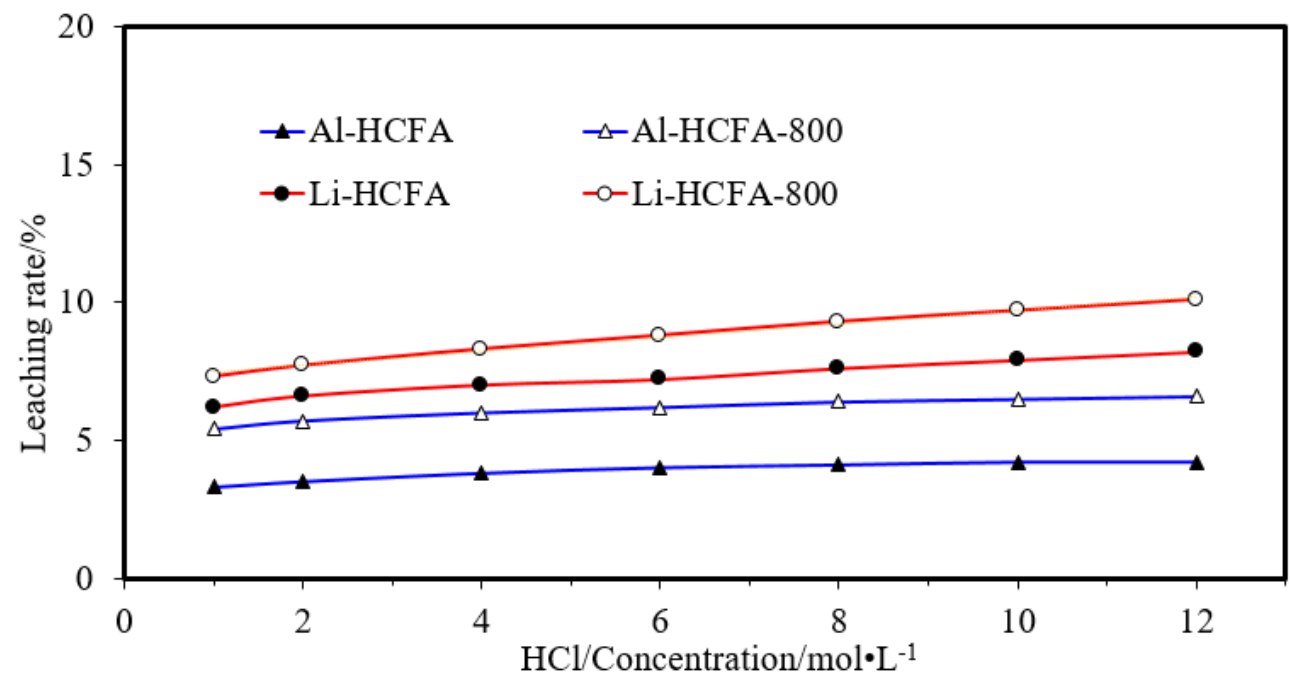

Figure 3. Leaching rate of HFCA and roasted HFCA at $800^{\circ} \mathrm{C}$ via direct acid leaching. 


\subsection{Thermal Activation on Leaching Process}

\subsubsection{Water Leaching}

The effect that water leaching at roasting temperatures in the range of $500-1000{ }^{\circ} \mathrm{C}$ with a $\mathrm{NaCl}-\mathrm{HCFA}$ mass ratio of 1:2 had on the dissolution of $\mathrm{Al}$ and $\mathrm{Li}$ in the HFCA slag was investigated using the same leaching conditions.

As seen in Figure 4, the dissolution of $\mathrm{Al}$ and $\mathrm{Li}$ is affected by roasting temperature, where rich aluminum and lithium minerals are roasted at a medium temperature. The water leaching rate of $\mathrm{Al}$ increased from $3.5 \%$ to $13 \%$ and that of $\mathrm{Li}$ increased from $6.9 \%$ to $17 \%$ when the sample was roasted from $500{ }^{\circ} \mathrm{C}$ to $800{ }^{\circ} \mathrm{C}$ for $60 \mathrm{~min}$. With an increase in the roasting temperature, the dissolution of Al slightly decreased, and the same trend was observed for Li dissolution above $900{ }^{\circ} \mathrm{C}$ Meanwhile, the apparent density of the roasted HCFA remained basically unchanged in the temperature range of $500{ }^{\circ} \mathrm{C}$ to $700{ }^{\circ} \mathrm{C}$, and then it increased remarkably above $700{ }^{\circ} \mathrm{C}$. In the process of roasting samples, the caking and hardening of roasting slag is serious; the slag had to be crushed, and this is not mentioned in previous studies. The results suggest that when the roasting temperature is below $700{ }^{\circ} \mathrm{C}$, the energy provided is inadequate to generate sintering and cause detectable conversion. Hence, the consequential changes occur in the temperature range from $700{ }^{\circ} \mathrm{C}$ to $1000{ }^{\circ} \mathrm{C}$, and this is consistent with earlier research [3].

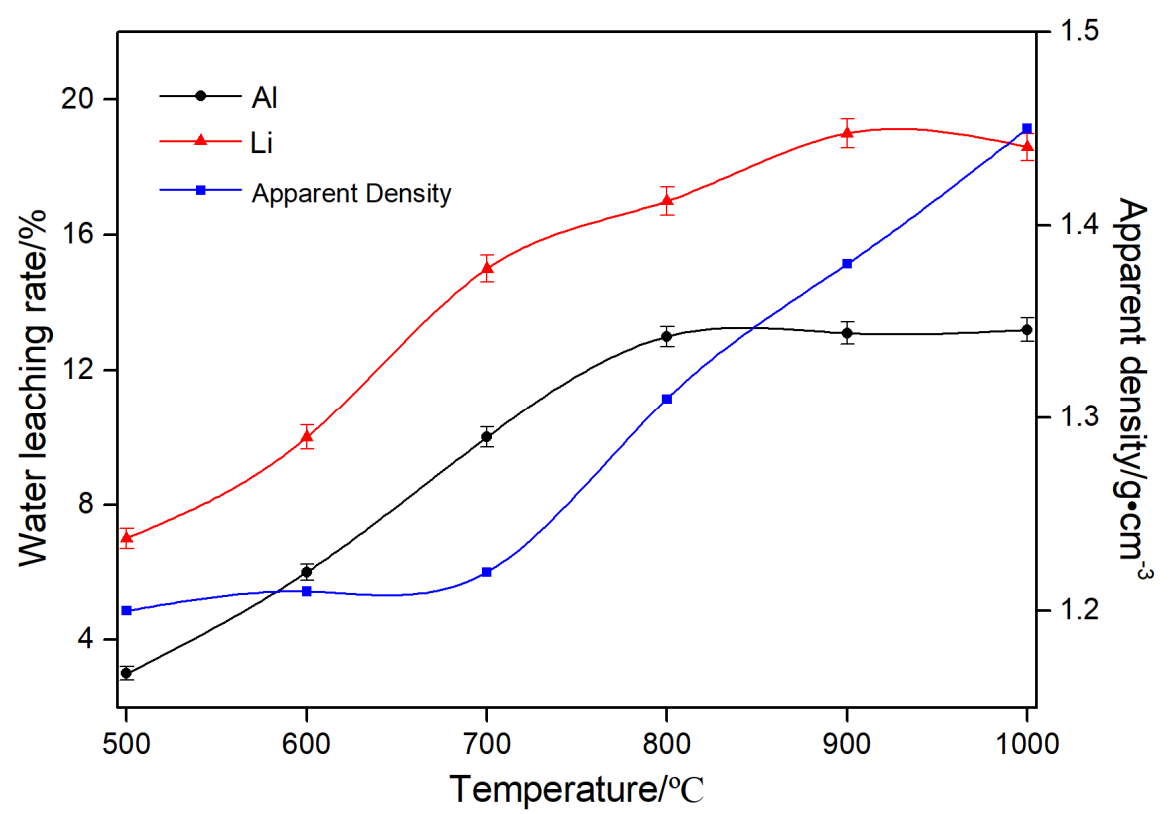

Figure 4. Effect of roasting temperature on water leaching rate and apparent density.

\subsubsection{Atmospheric Pressure Acid Leaching}

Figure 5 shows that both the increase in the roasting temperature and the $\mathrm{NaCl}$ mass ratio promoted the extraction efficiency of $\mathrm{Al}$ and $\mathrm{Li}$. On the whole, the extraction efficiency of $\mathrm{Al}$ was higher than that of $\mathrm{Li}$, and this is different from the trends observed for direct acid leaching. With an increase in the HCFA-NaCl mass ratio from 2 to 0.5 at $650{ }^{\circ} \mathrm{C}$, the extraction efficiency of $\mathrm{Al}$ increased from $50.2 \%$ to $52.7 \%$ and that of $\mathrm{Li}$ increased from $31.2 \%$ to $45.4 \%$. Because of the increasing leaching temperature, more aluminum silicate was activated via the sodium calcination process. However, the extraction efficiency of Li increased slowly when the roasting temperature reached $950{ }^{\circ} \mathrm{C}$, while Al was still extracted steadily. This indicates that the higher temperature enhanced the solid phase reaction between $\mathrm{NaCl}$ and aluminosilicate minerals. Also, the structure of mullite is the main phase that is decomposed into soluble salt, which is more conducive for extraction. This process is provable from the XRD analysis of mixed roasted samples, as shown in Figure 6. 

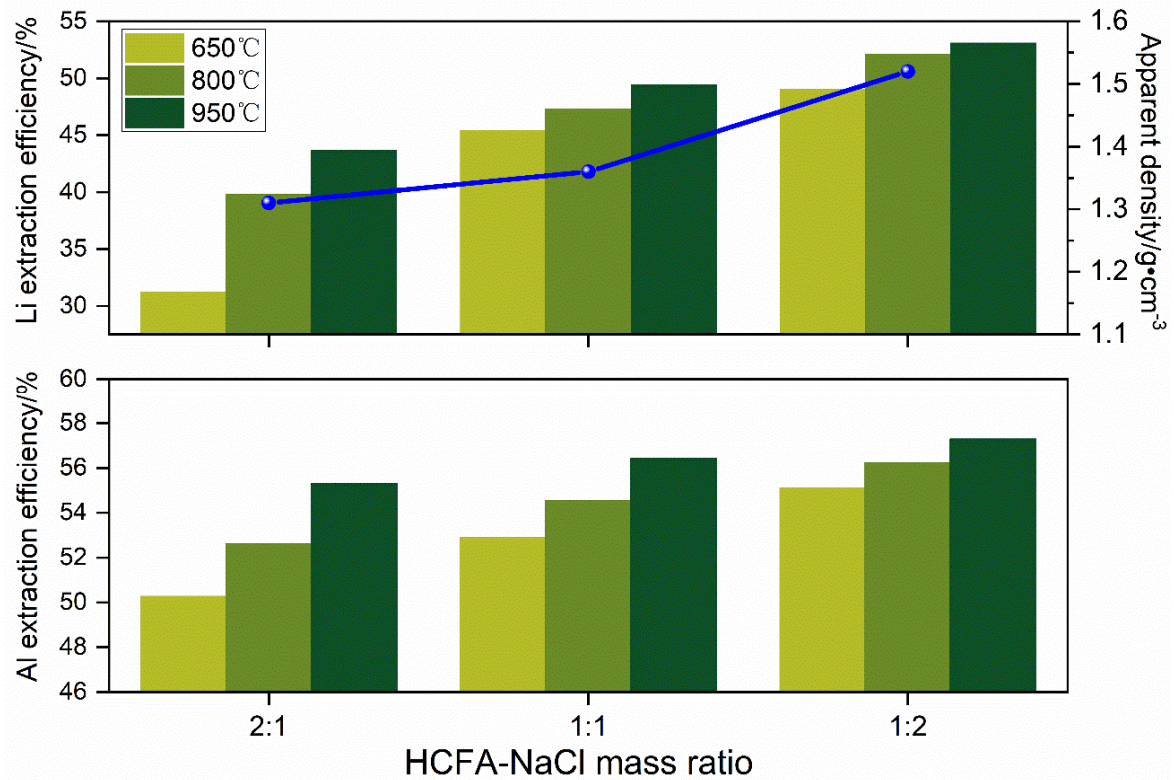

Figure 5. Effect of roasting temperature and $\mathrm{NaCl}$ content on the direct extraction efficiency.

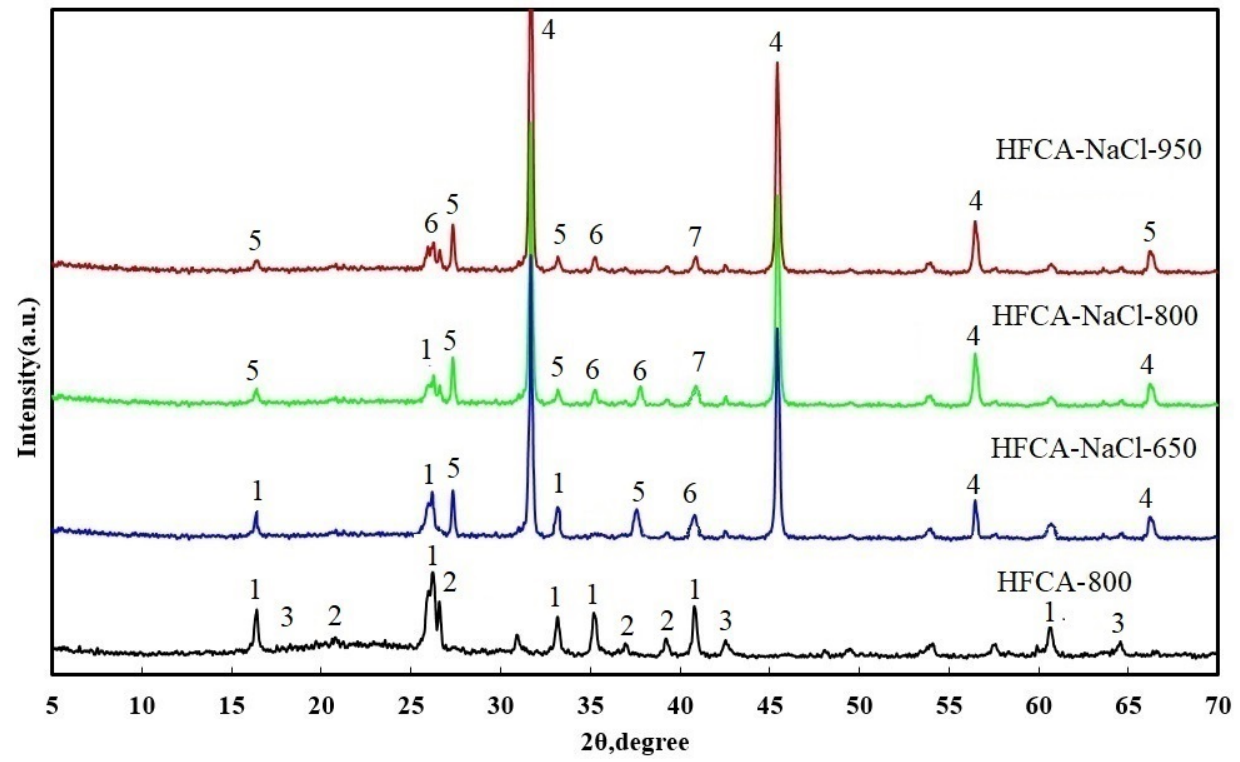

Figure 6. XRD spectra of HFCA roasted with the addition of $\mathrm{NaCl}$. $1-3 \mathrm{Al}_{2} \mathrm{O}_{3} \cdot 2 \mathrm{SiO}_{2}$ (Mullite); $2-\mathrm{SiO}_{2}$ (Quartz); 3- $\mathrm{Al}_{2} \mathrm{SiO}_{5}$ (Sillimanite); $4-\mathrm{NaCl}$ (Halite); $5-\mathrm{NaAlSiO}_{4}$ (Sodium aluminum silicate); $6-\mathrm{NaCaAlSi}_{2} \mathrm{O}_{7}$. (Melilite); $7-\mathrm{NaAlSi}_{2} \mathrm{O}_{6}$ (Jadeite).

The extraction efficiency of $\mathrm{Al}$ and Li increased slowly with an increase in the mass of $\mathrm{NaCl}$ because of the reaction of sodium and aluminum silicate. When the HCFA-NaCl mass ratio reached 1:1 at $800{ }^{\circ} \mathrm{C}$, the extraction efficiencies of $\mathrm{Al}$ and $\mathrm{Li}$ were both over $50 \%$. When it was increased to $1: 2$, no more Li was extracted, whereas Al was still further extracted. Additionally, the apparent density increased rapidly, exceeding 1.5, and this results in caking of the roasted mixture, which is difficult to crush and grind. This can be attributed to the sodium roasting reaction and the liquation of $\mathrm{NaCl}$ at a temperature around the melting temperature. Thus, a HCFA-NaCl mass ratio of $1: 1$ at $800{ }^{\circ} \mathrm{C}$ was selected as the optimum roasting conditions. 


\subsubsection{Phase Transformation Characterization}

To clarify the activation influence of $\mathrm{NaCl}$ on HCFA and further mechanism research, XRD was used to analyze the crystalline phase structure. Figure 6 shows the XRD patterns of roasted powders that were obtained via roasting HFCA with $\mathrm{NaCl}$ at a mass ratio of $1: 1$ for $2 \mathrm{~h}$ at different temperatures; the XRD pattern of $\mathrm{HCFA}$ roasted at $800{ }^{\circ} \mathrm{C}$ is included for comparison. It is observed that mullite was still the major mineral phases in HCFA after roasting at $650^{\circ} \mathrm{C}$. The aluminosilicate minerals generated in coal combustion. The cooling process had higher stability and did not decompose when it was roasted alone. This indicates that it was difficult for the $\mathrm{Al}$ and $\mathrm{Li}$ in polymeric aluminosilicate to be dissolved via water and direct $\mathrm{HCl}$ leaching (Figures 3 and 4).

When $\mathrm{NaCl}$ was added, the XRD trace shows that there are obviously new peak profiles at different roasting temperatures. The new crystalline minerals identified are halite, sodium aluminum silicate, jadeite, and melilite, and the peak intensity of mullite and quartz became weak with the increase in roasting temperature. The quartz phase gradually disappeared when the temperature was above $650{ }^{\circ} \mathrm{C}$; this was very relevant to the reaction with additive, and sodium aluminum silicate began to appear. Meanwhile, the mullite phase that was identified decreased dramatically, and this was attributed to the decomposition of aluminosilicate minerals via the action of $\mathrm{NaCl}$ under the roasting conditions. Furthermore, the new phases were more reactive with acid, and this is consistent with the extraction efficiency trends of $\mathrm{Al}$ and $\mathrm{Li}$, as seen in Figures 4 and 5. The results are approximately consistent with the conclusion [4] that there were large amounts of $\mathrm{NaAlSiO}_{4}$ and jadeite generated after calcination when $\mathrm{NaOH}$ and $\mathrm{Na}_{2} \mathrm{CO}_{3}$ were added. The extraction efficiency of $\mathrm{Al}$ and $\mathrm{Li}$ at mixed roasting conditions was greater than 10 times the direct acid leaching rate. With a temperature increase to $950{ }^{\circ} \mathrm{C}$, the mullite phase completely disappeared, the high intensity of halite further increased, and sodium aluminum silicate became the main Al-rich phase.

\subsubsection{FactSage Thermodynamic Simulation}

Because of the detection limit of XRD, Li-bearing minerals cannot be identified conclusively. Computer-assisted thermodynamic modeling of phase equilibria helps in predicting processes and chemical compositions at equilibrium [18]. The phase distributions for the roasted samples with sodium chloride in an atmosphere of air are illustrated in Figure 7. As seen in Figure 7a, in the temperature range of $400-1100{ }^{\circ} \mathrm{C}$, some new phases (such as $\mathrm{NaAlSi}_{3} \mathrm{O}_{8}, \mathrm{Al}_{2} \mathrm{SiO}_{5}$, and $\mathrm{LiCl}$ ) were generated. Above $700{ }^{\circ} \mathrm{C}$ more $\mathrm{Al}_{2} \mathrm{SiO}_{5}$ was reacted with $\mathrm{NaCl}$ to produce $\mathrm{NaAlSi}_{3} \mathrm{O}_{8}$. Figure $7 \mathrm{~b}-\mathrm{d}$ shows Al-bearing, Li-bearing, and Na-bearing minerals appear in the roasting process.

Li-bearing minerals were only $\mathrm{LiCl}$, and turned into liquid above $600{ }^{\circ} \mathrm{C}$, and then it was all $\mathrm{LiCl}$ liquid around $800{ }^{\circ} \mathrm{C}$. The melting point of $\mathrm{NaCl}$ is $801^{\circ} \mathrm{C}$, and this further confirmed the increase of the apparent density at high temperature. Some of the minerals were vaporized into the gas phase. Hence, there was a definite loss of lithium when the HCFA was roasted with $\mathrm{NaCl}$ at high temperature. The formulae of Al-bearing minerals were recognized as $\mathrm{Al}_{2} \mathrm{SiO}_{5}$ and $\mathrm{Al}_{2} \mathrm{O}_{3}$, but it went through different forms of mineral constituents; specifically, it transformed into andalusite, albite, sillimanite, and $\alpha-\mathrm{Al}_{2} \mathrm{O}_{3}$ with an increase in temperature. Na-bearing minerals were mainly present in the form of halite and albite. 

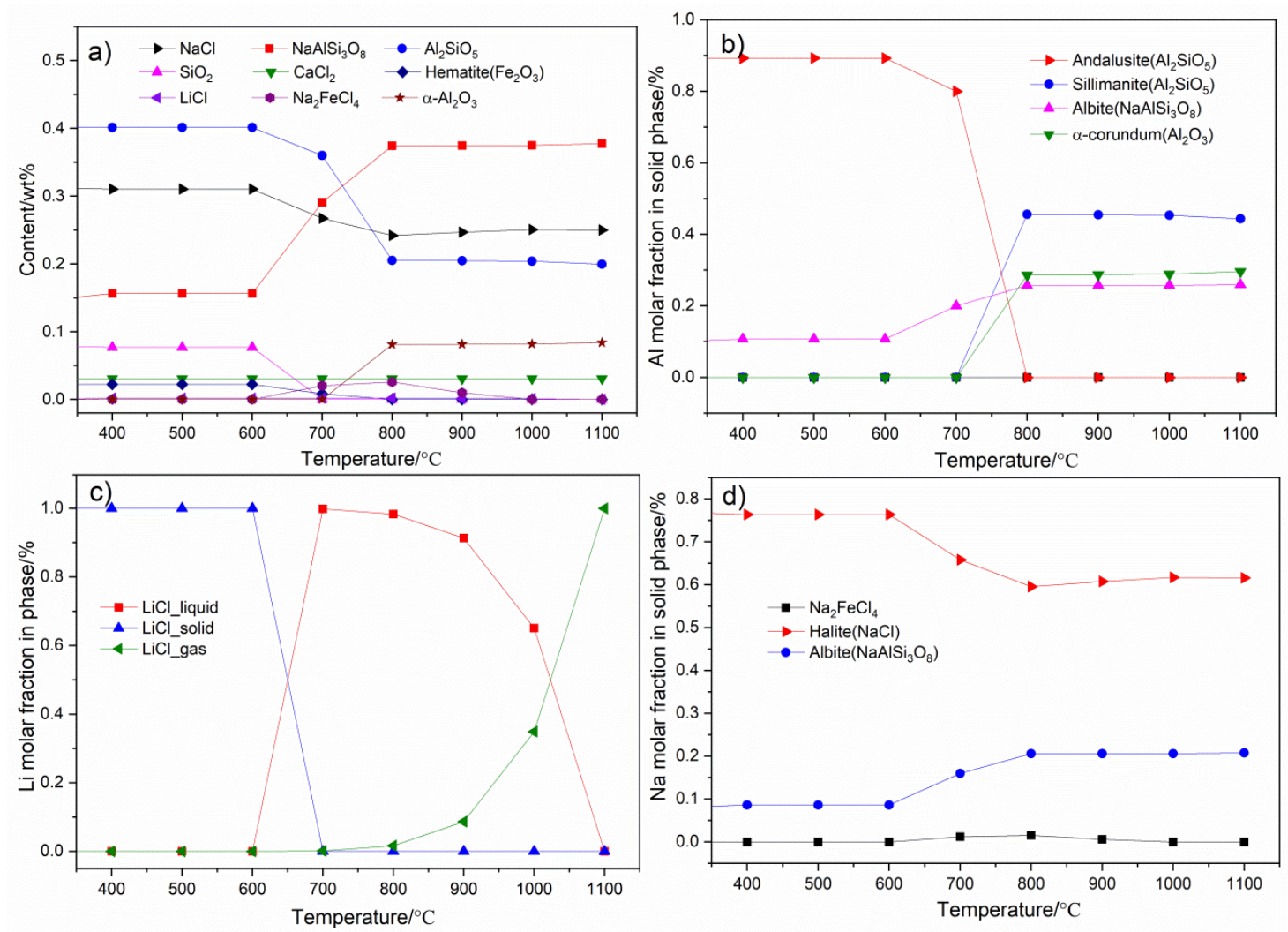

Figure 7. Phase transformation and distribution with the temperature calculated by FactSage. (a) Phase transformation; (b) Al-bearing minerals; (c) Li-bearing minerals; (d) Na-bearing minerals.

Generally, pure $\mathrm{NaCl}$ is very stable and hard to decompose, but with an increase in temperature and with the presence of aluminum, silicon, iron, etc., $\mathrm{NaCl}$ shows high reactivity. There have been many studies that confirm the following reaction processes (1) and (2) $[19,20]$. In this case, reaction (1) was definitely dominant for these roasting conditions.

$$
\begin{gathered}
2 \mathrm{NaCl}+\mathrm{O}_{2}=\mathrm{Na}_{2} \mathrm{O}+\mathrm{Cl}_{2} \\
2 \mathrm{NaCl}+\mathrm{H}_{2} \mathrm{O}(\mathrm{g})=\mathrm{Na}_{2} \mathrm{O}+2 \mathrm{HCl}
\end{gathered}
$$

The new products $\mathrm{NaAlSiO}_{4}, \mathrm{NaCaAlSi}_{2} \mathrm{O}_{7}$, and $\mathrm{NaAlSi}_{2} \mathrm{O}_{6}$ correspond to roasting with the $\mathrm{NaCl}$ additive. They were generated because of stabilization that is caused by the presence of $\mathrm{Na}_{2} \mathrm{O}$. The following main reactions are proposed on the basis of the above discussions:

$$
\begin{gathered}
\mathrm{Li}_{2} \mathrm{O}+2 \mathrm{NaCl} \rightarrow 2 \mathrm{LiCl}+\mathrm{Na}_{2} \mathrm{O} \\
3 \mathrm{Al}_{2} \mathrm{O}_{3} \cdot 2 \mathrm{SiO}_{2}+3 \mathrm{Na}_{2} \mathrm{O}+4 \mathrm{SiO}_{2} \rightarrow 6 \mathrm{NaAlSiO}_{4} \\
3 \mathrm{Al}_{2} \mathrm{O}_{3} \cdot 2 \mathrm{SiO}_{2}+3 \mathrm{Na}_{2} \mathrm{O}+10 \mathrm{SiO}_{2}+6 \mathrm{CaO} \rightarrow 6 \mathrm{NaCaAlSi}_{2} \mathrm{O}_{7} \\
3 \mathrm{Al}_{2} \mathrm{O}_{3} \cdot 2 \mathrm{SiO}_{2}+3 \mathrm{Na}_{2} \mathrm{O}+10 \mathrm{SiO}_{2} \rightarrow 6 \mathrm{NaAlSi}_{2} \mathrm{O}_{6}
\end{gathered}
$$

The $\mathrm{Na}_{2} \mathrm{O}-\mathrm{Al}_{2} \mathrm{O}_{3}-\mathrm{SiO}_{2}$ ternary system is an important system in fused salt chemistry and geology and has therefore mainly been studied in cases where sodium-containing substances (such as $\mathrm{Na}_{2} \mathrm{CO}_{3}$, $\mathrm{Na}_{2} \mathrm{SO}_{4}$, and $\mathrm{NaCl}$ ) were added to aluminosilicate minerals. Some researchers [21,22] critically assessed the thermodynamic and phase diagram for the condensed phases of the ternary system. The addition of sodium to the tetrahedral network facilitates formation of $(\mathrm{NaAl})^{4+}$ via association of $\mathrm{Al}^{3+}$ with $\mathrm{Na}^{+}$. 


\subsection{Pressure Acid Leaching}

\subsubsection{Effects of Initial Acid Concentration}

The extraction efficiency of $\mathrm{Al}$ and $\mathrm{Li}$ was low (around 60\%) when the direct acid experiment was conducted with sufficient acid. The main minerals, such as mullite, were just partially converted into Na-bearing minerals, which are soluble in acid. To maximize the extraction of $\mathrm{Al}$ and $\mathrm{Li}$, the acid leaching process was carried out in a closed reaction system. During the heating process, the $\mathrm{HCl}$ solution was vaporized into the gas phase, and self-pressure was rapidly generated. Figure 8 shows the effect of that initial acid concentration on the extraction efficiency of $\mathrm{Al}$ and $\mathrm{Li}$ at a leaching temperature of $120^{\circ} \mathrm{C}$ under pressure. The extraction of $\mathrm{Al}$ and $\mathrm{Li}$ increased with time and with an increase in the initial concentration from 2.0 to $8.0 \mathrm{~mol} / \mathrm{L}$. With $6 \mathrm{~mol} / \mathrm{L} \mathrm{HCl}$ and $120 \mathrm{~min} .93 .1 \%$ of $\mathrm{Al}$ and $96.2 \%$ of $\mathrm{Li}$ were extracted. Under the pressure of an acidic atmosphere, a heterogeneous noncatalytic solid-liquid-gas reaction occurred. The proton-attacking mechanism can be explained as the dissolution of $\mathrm{Al}$ and $\mathrm{Li}$ [23]. The dissolution trends of $\mathrm{Al}$ and $\mathrm{Li}$ were similar to the trend of the influence that the initial acid concentration had. Li was almost completely extracted after $150 \mathrm{~min}$, and this confirmed the leaching correlation between $\mathrm{Al}$ and $\mathrm{Li}$ under direct and pressure acid leaching. After Si-O-Si or Si-O-Al bonds were broken by $\mathrm{NaCl}$ fusion, the wrapped Li-bearing minerals were released via acid leaching. Combined with the results shown in Figure 7, $\mathrm{LiCl}$ was more soluble in the $\mathrm{HCl}$ solution. More clearly, compared to the pressure extraction technology in our previous research [3,24], the dissolution processes were accelerated quickly from $4 \mathrm{~h}$ to $2 \mathrm{~h}$, and this is definitely attributed to the roasting process, which cracks the mullite that is insoluble in acid.
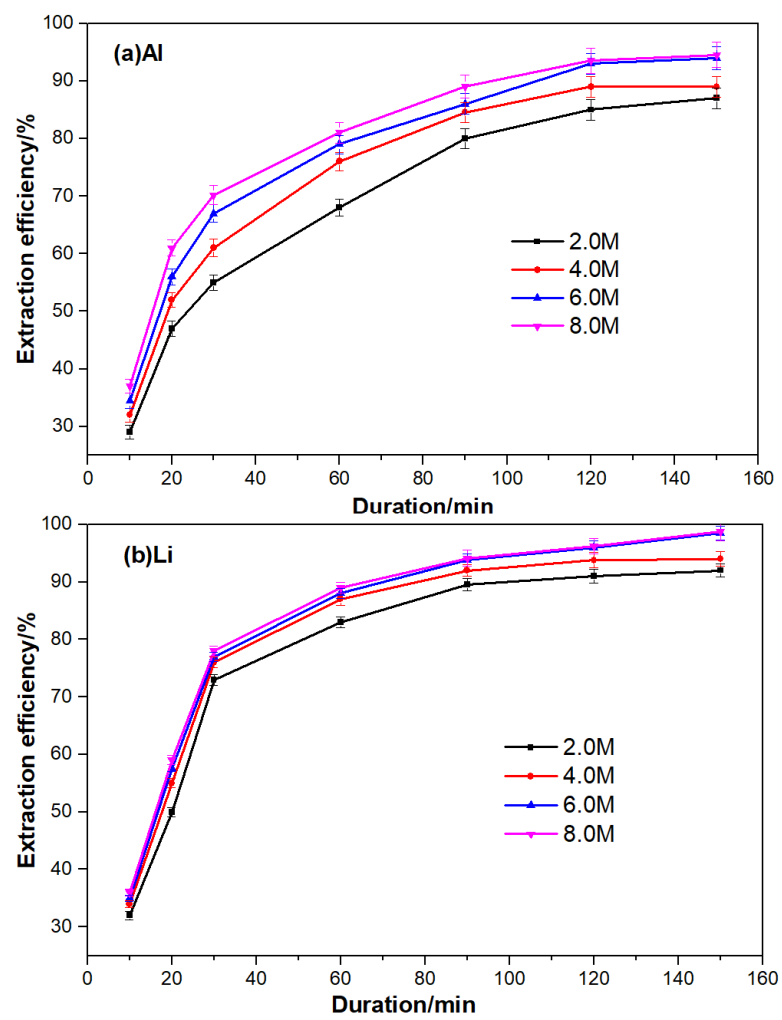

Figure 8. Effects of initial concentration on the extraction efficiency of (a) aluminum, (b) lithium at $120^{\circ} \mathrm{C}$.

Moreover, the $\mathrm{Al}$ extraction efficiency depends on leaching kinetics in $\mathrm{HCl}$ solution, and the effects of this have been studied on the leaching of common coal fly ash in a few reports in the literatures $[23,25]$. From the perspective of leaching kinetics, the increase in $\mathrm{HCl}$ concentration effectively promotes the dissolution of $\mathrm{Al}$, but the solubility of aluminum chloride hexahydrate decreases with an increase in 
the mass of $\mathrm{HCl}$, sodium, and potassium chloride in the solution system [26]. As the leaching reaction continued, the $\mathrm{AlCl}_{3}$ in solution system became saturated, the Al-bearing minerals dissolved, and precipitation maintained a dynamic equilibrium. The leaching process was inhibited, and this might explain the $\mathrm{Al}$ and $\mathrm{Li}$ leaching behavior and limited extraction efficiency when the concentration of the $\mathrm{HCl}$ solution was high. Moreover, maybe little mullite and corundum still remained in the residue. Hence, $6 \mathrm{M} \mathrm{HCl}$ and $2 \mathrm{~h}$ were selected as the optimum conditions for $\mathrm{Al}$ and $\mathrm{Li}$ extraction.

\subsubsection{Effects of Temperature}

As is shown in Figure 9, for the extraction behavior of $\mathrm{Al}$ and $\mathrm{Li}$ with increasing temperature, it was observed that there was both an increasing trend in the extraction of aluminum and lithium with $6 \mathrm{M}$ hydrochloric acid and S/L ratio of $1: 20 \mathrm{~g} / \mathrm{cm}^{3}$. About $94.2 \%$ of the available aluminum and $98.9 \%$ of lithium were extracted at $150^{\circ} \mathrm{C}$ after $120 \mathrm{~min}$, and this exceeded the azeotropic point, which is at $106{ }^{\circ} \mathrm{C}$ for $6 \mathrm{~mol} / \mathrm{L} \mathrm{HCl}$ solution. Therefore, extractions at $60{ }^{\circ} \mathrm{C}$ and $90{ }^{\circ} \mathrm{C}$ were attained with $\mathrm{HCl}$ in the liquid phase whereas extractions at $120^{\circ} \mathrm{C}$ and $150^{\circ} \mathrm{C}$ were achieved in the gas phase. In general, when the temperature is higher, the extraction efficiency is higher.
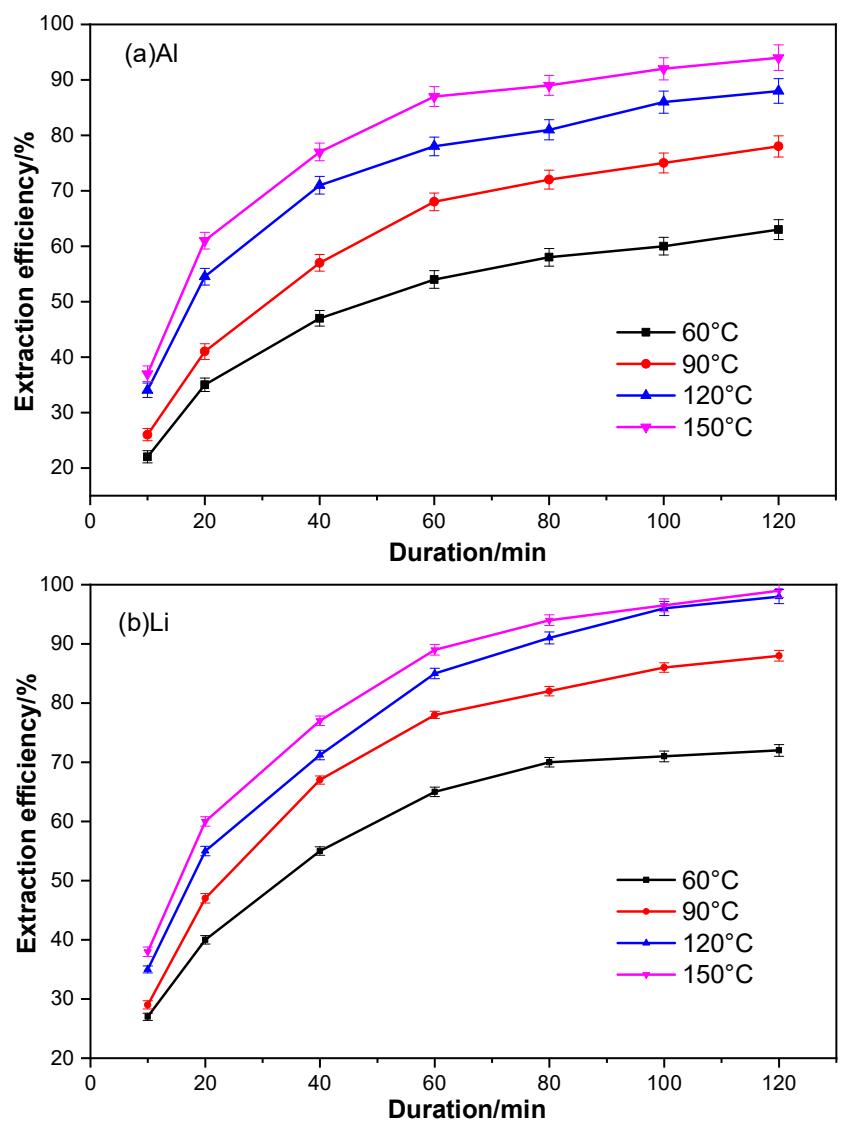

Figure 9. Effect of reaction temperature on the extraction efficiency of (a) aluminum, (b) lithium using $6 \mathrm{~mol} / \mathrm{L} \mathrm{HCl}$.

Introduction of a pressurized atmosphere into the pretreatment process greatly influences the extraction efficiency, increasing it by a factor of nearly two. Dissolution of aluminum and lithium is very sensitive to temperature between $60^{\circ} \mathrm{C}$ and $120^{\circ} \mathrm{C}$. However, the sharp increasing trend starts to flatten after $80 \mathrm{~min}$. The results are consistent with previous research [3]. As a rule, $\mathrm{Al}_{2} \mathrm{O}_{3}$ dissolution is due to the interface and is diffusion-limited at various temperatures. The diffusion and reaction process were accelerated under pressure leaching. However, about $10 \%$ of the aluminum still remained in the residue at $150{ }^{\circ} \mathrm{C}$, and except for the reason that this is attributed to the low solubility of $\mathrm{AlCl}_{3}$ 
in high concentration $\mathrm{HCl}$ solution [26], the formation of silicic acid could hinder the diffusion and reaction of $\mathrm{H}^{+}$with Al-bearing minerals. Compared to $\mathrm{AlCl}_{3}$, although there was less lithium in $\mathrm{HCFA}$, lithium chloride has stronger solubility.

\subsubsection{Surface Morphology Change}

To describe the effects of the roasting and leaching processes more visually, the origin HCFA, roasted samples with $\mathrm{HCFA}$ to $\mathrm{NaCl}$ mass ratios of 2:1 and 1:2 at $950{ }^{\circ} \mathrm{C}$, and the leached residue were observed using SEM. The results are shown in Figure 10, which shows that the particle distribution is magnified by factors of 1000 and 2000. The minority of the particles in the original HCFA (Figure 10a) was relatively smooth and compact solid spheres, which is a typical characteristic of coal fly ash. After roasting, the particles became more porous and rough, and then they blended together with $\mathrm{NaCl}$ melt (Figure 10b). The molten mass grew and became irregular as the amount of $\mathrm{NaCl}$ increased (Figure 10c), and this is consistent with the increase in the apparent density (Figure 4). This most likely occurred because the particles adhered and were surrounded by excess molten $\mathrm{NaCl}$. Also, frit reactions were inhibited, which is reasonably explained by the smaller particles being conducive to the roasting process. After sieving and pressure leaching, the samples became fragmented, and the spherical particles were broken open. Moreover, the surface of the residue was fluffy and loose. Therefore, it could be concluded that sodium roasting is feasible for activating HFCA, but it may result in a caking problem when excess sodium chloride is used.
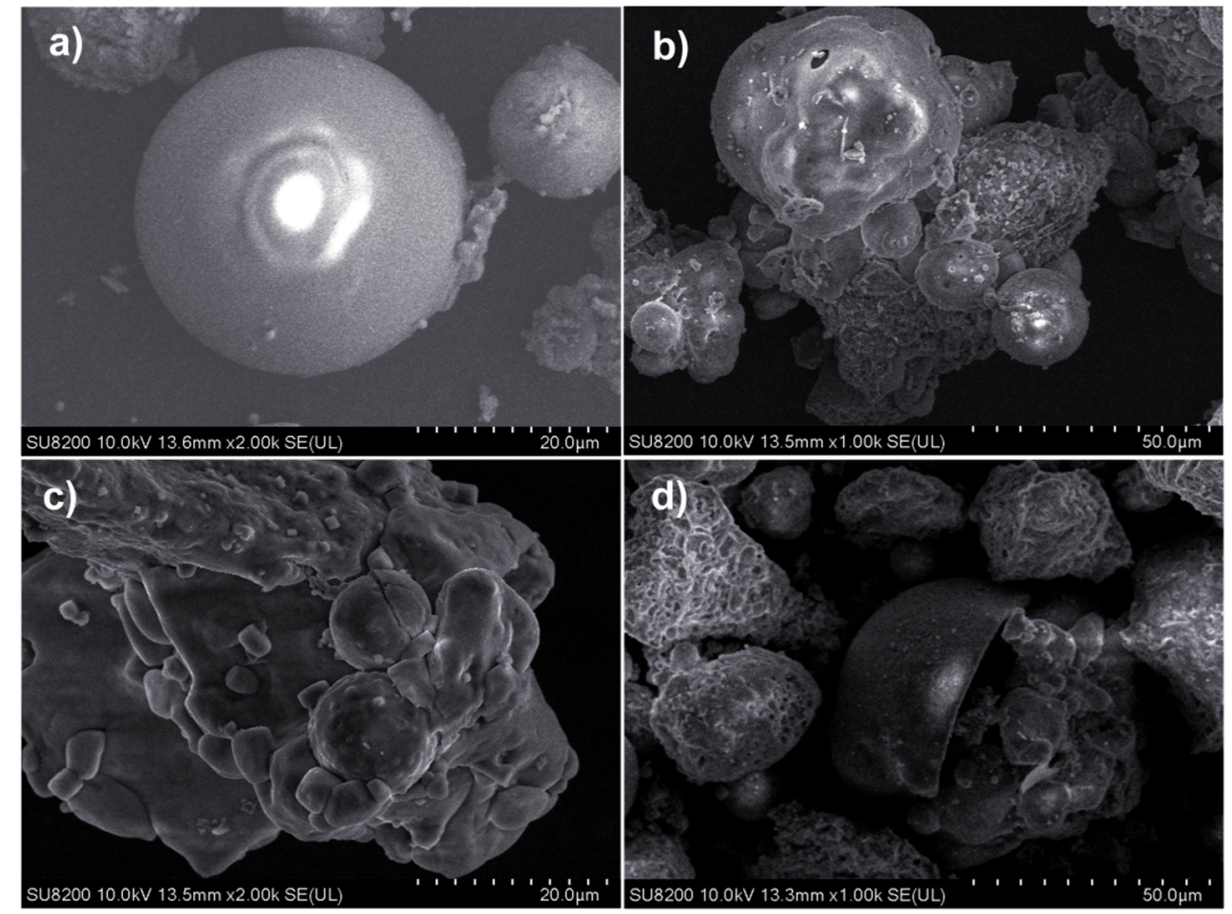

Figure 10. SEM images of samples obtained from roasted and leaching steps $((\mathbf{a})$ - HCFA; $(\mathbf{b}, \mathbf{c})$-roasted samples with HCFA to $\mathrm{NaCl}$ mass ratio of 2:1 and 1:2; (d)-leached residue).

\section{Conclusions}

To develop a high-efficiency roasting and leaching technology for extracting aluminum and lithium from high-alumina coal fly ash, this article investigated HCFA pressure leaching behavior with hydrochloric acid after sodium roasting. The major phases in the HCFA were mullite, quartz, and corundum. The leaching rate of $\mathrm{Al}$ and $\mathrm{Li}$ is very limited when direct water and acid leaching were used. After roasting with sodium chloride, about 13\% Al and 17\% Li were washed out with water. The extraction efficiency of $\mathrm{Al}$ and Li reached about 50\% when $4 \mathrm{~mol} /$ Lhydrochloric acid was used at a 
leaching temperature of $120^{\circ} \mathrm{C}$. Adding excess $\mathrm{NaCl}$ can result in serious agglomeration. XRD and SEM results showed that adding $\mathrm{NaCl}$ and increasing the temperature can promote decomposition of mullite into soluble sodium salts. Finally, compared with predesilication, the roasting and pressure acid leaching method for extracting aluminum and lithium results in fewer residues and higher extraction efficiencies.

Author Contributions: Conceptualization, S.L.; Data curation, P.B.; Formal analysis, H.G.; Funding acquisition, S.Q.; Investigation, P.B.; Methodology, L.K.; Project administration, S.Q.; Software, S.L.; Writing-original draft, S.L.; Writing-review and editing, W.G. All authors have read and agreed to the published version of the manuscript.

Funding: This research was funded by the Natural Science Foundation of Hebei Province, grant nos. D2019402181 and D2018402093; the Key Science and Technology Foundation in Universities of Hebei Province, grant no. ZD2019055; and Hebei Provincial Project for Training and Supporting Talent, grant no. A201802006.

Acknowledgments: The authors are grateful to the School of Earth Science and Engineering, Materials Science and Engineering, Hebei University of Engineering (HUE) for supporting this study.

Conflicts of Interest: The authors declare no conflict of interest.

\section{References}

1. Luo, Y.; Wu, Y.H.; Ma, S.H.; Zheng, S.L.; Zhang, Y.; Chu, P.K. Utilization of coal fly ash in China: A mini-review on challenges and future directions. Environ. Sci. Pollut. Res. 2020, 1-14. [CrossRef]

2. Wang, D.L.; Wan, K.D.; Yang, J.Y. Measurement and evolution of eco-efficiency of coal industry ecosystem in China. J. Clean Prod. 2019, 209, 803-818. [CrossRef]

3. Li, S.Y.; Qin, S.J.; Kang, L.W.; Liu, J.J.; Wang, J.; Li, Y.H. An efficient approach for lithium and aluminum recovery from coal fly ash by pre-desilication and intensified acid leaching processes. Metals 2017, 7, 272. [CrossRef]

4. Guo, Y.X.; Li, Y.Y.; Cheng, F.Q.; Wang, M.; Wang, X.M. Role of additives in improved thermal activation of coal fly ash for alumina extraction. Fuel Process. Technol. 2013, 110, 114-121. [CrossRef]

5. Hu, P.P.; Hou, X.J.; Zhang, J.B.; Li, S.P.; Wu, H.; Damø, A.J.; Li, H.Q.; Wu, Q.S.; Xi, X.G. Distribution and occurrence of lithium in high-alumina-coal fly ash. Int. J. Coal Geol. 2018, 189, 27-34. [CrossRef]

6. Valeev, D.; Kunilova, I.; Alpatov, A.; Mikhailova, A.; Goldberg, M.; Kondratiev, A. Complex utilisation of ekibastuz brown coal fly ash: Iron \& carbon separation and aluminum extraction. J Clean. Prod. 2019, 218, 192-201.

7. Qin, S.J.; Zhao, C.L.; Li, Y.H.; Zhang, Y. Review of coal as a promising source of lithium. Int. J. Oil Gas Coal Technol. 2015, 9, 215-229. [CrossRef]

8. Sun, L.Y.; Luo, K.; Fan, J.R.; Lu, H.L. Experimental study of extracting alumina from coal fly ash using fluidized beds at high temperature. Fuel 2017, 199, 22-27. [CrossRef]

9. Shemi, A.; Ndlovu, S.; Sibanda, V.; Van Dyk, L.D. Extraction of alumina from coal fly ash using an acid leach-sinter-acid leach technique. Hydrometallurgy 2015, 157, 348-355. [CrossRef]

10. Gao, Y.; Liang, K.; Gou, Y.; Wei, S.; Shen, W.; Cheng, F. Aluminum extraction technologies from high aluminum fly ash. Rev. Chem. Eng. 2020. [CrossRef]

11. Gollakota, A.R.; Volli, V.; Shu, C.M. Progressive utilisation prospects of coal fly ash: A review. Sci. Total Environ. 2019, 672, 951-989. [CrossRef] [PubMed]

12. Swain, B. Recovery and recycling of lithium: A review. Sep. Purif. Technol. 2017, 172, 388-403. [CrossRef]

13. Flexer, V.; Baspineiro, C.F.; Galli, C.I. Lithium recovery from brines: A vital raw material for green energies with a potential environmental impact in its mining and processing. Sci. Total Environ. 2018, 639, 1188-1204. [CrossRef] [PubMed]

14. Seredin, V.V.; Dai, S.; Sun, Y.; Chekryzhov, I.Y. Coal deposits as promising sources of rare metals for alternative power and energy-efficient technologies. Appl. Geochem. 2013, 31, 1-11. [CrossRef]

15. Querol, X.; UmanÄa, J.C.; Alastuey, A.; Ayora, C.; Lopez-Soler, A.; Plana, F. Extraction of soluble major and trace elements from fly ash in open and closed leaching systems. Fuel 2001, 80, 801-813. [CrossRef]

16. Jak, E.; Hayes, P.; Bale, C.W.; Decterov, S.A. Application of FactSage thermodynamic modeling of recycled slags $\left(\mathrm{Al}_{2} \mathrm{O}_{3}-\mathrm{CaO}-\mathrm{FeO}-\mathrm{Fe}_{2} \mathrm{O}_{3}-\mathrm{SiO}_{2}-\mathrm{PbO}-\mathrm{ZnO}\right)$ in the treatment of wastes from end-of-life-vehicles. Int. J. Mater. Res. 2007, 98, 872-878. [CrossRef] 
17. Chen, C.Y.; Lan, G.S.; Tuan, W.H. Preparation of mullite by the reaction sintering of kaolinite and alumina. J. Eur. Ceram. Soc. 2000, 20, 2519-2525. [CrossRef]

18. Wang, G.L.; Jensen, P.A.; Wu, H.; Frandsen, F.J.; Laxminarayan, Y.; Sander, B.; Glarborg, P. KOH capture by coal fly ash. Fuel 2019, 242, 828-836. [CrossRef]

19. Zeng, X.; Wang, F.; Zhang, H.F.; Cui, L.J.; Yu, J.; Xu, G.W. Extraction of vanadium from stone coal by roasting in a fluidized bed reactor. Fuel 2015, 142, 180-188. [CrossRef]

20. Wang, M.Y.; Wang, X.W.; Shen, J.F.; Wu, R. Extraction of vanadium from stone coal by modified salt-roasting process. J. Cent. South Univ. Technol. 2011, 18, 1940-1944. [CrossRef]

21. Lambotte, G.; Chartrand, $\mathrm{P}$. Thermodynamic modeling of the $\left(\mathrm{Al}_{2} \mathrm{O}_{3}+\mathrm{Na}_{2} \mathrm{O}\right),\left(\mathrm{Al}_{2} \mathrm{O}_{3}+\mathrm{Na}_{2} \mathrm{O}+\mathrm{SiO}_{2}\right)$, and $\left(\mathrm{Al}_{2} \mathrm{O}_{3}+\mathrm{Na}_{2} \mathrm{O}+\mathrm{AlF}_{3}+\mathrm{NaF}\right)$ systems. J. Chem. Thermodyn. 2013, 57, 306-334. [CrossRef]

22. Chartrand, P.; Pelton, A.D. Modeling the charge compensation effect in silica-rich $\mathrm{Na}_{2} \mathrm{O}-\mathrm{K}_{2} \mathrm{O}-\mathrm{Al}_{2} \mathrm{O}_{3}-\mathrm{SiO}_{2}$ melts. Calphad 1999, 23, 219-230. [CrossRef]

23. Luo, Q.; Chen, G.L.; Sun, Y.Z.; Ye, Y.M.; Qiao, X.C.; Yu, J.G. Dissolution kinetics of aluminum, calcium, and iron from circulating fluidized bed combustion fly ash with hydrochloric acid. Ind. Eng. Chem. Res. 2013, 52, 18184-18191. [CrossRef]

24. Wu, C.Y.; Yu, H.F.; Zhang, H.F. Extraction of aluminum by pressure acid-leaching method from coal fly ash. Trans. Nonferrous Metal. Soc. 2012, 22, 2282-2288. [CrossRef]

25. Cui, L.; Guo, Y.X.; Wang, X.M.; Du, Z.P.; Cheng, Z.P.; Cheng, F.Q. Dissolution kinetics of aluminum and iron from coal mining waste by hydrochloric acid. Chin. J. Chem. Eng. 2015, 23, 590-596. [CrossRef]

26. Christov, C.; Dickson, A.G.; Moller, N. Thermodynamic modeling of aqueous aluminum chemistry and solid-liquid equilibria to high solution concentration and temperature. J. Solut. Chem. 2007, 36, 1495-1523. [CrossRef]

(C) 2020 by the authors. Licensee MDPI, Basel, Switzerland. This article is an open access article distributed under the terms and conditions of the Creative Commons Attribution (CC BY) license (http://creativecommons.org/licenses/by/4.0/). 